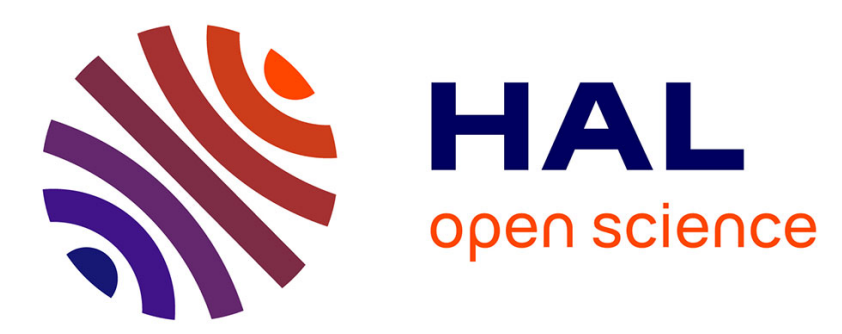

\title{
Mechanisms involved in thermal diffusion of rare earth elements in apatite
}

\author{
P. Martin, G. Carlot, A. Chevarier, C. Den-Auwer, G. Panczer
}

\section{To cite this version:}

P. Martin, G. Carlot, A. Chevarier, C. Den-Auwer, G. Panczer. Mechanisms involved in thermal diffusion of rare earth elements in apatite. Journal of Nuclear Materials, 1999, 275, pp.268-276. in2p3-00002423

\section{HAL Id: in2p3-00002423 \\ https://hal.in2p3.fr/in2p3-00002423}

Submitted on 30 Nov 1999

HAL is a multi-disciplinary open access archive for the deposit and dissemination of scientific research documents, whether they are published or not. The documents may come from teaching and research institutions in France or abroad, or from public or private research centers.
L'archive ouverte pluridisciplinaire HAL, est destinée au dépôt et à la diffusion de documents scientifiques de niveau recherche, publiés ou non, émanant des établissements d'enseignement et de recherche français ou étrangers, des laboratoires publics ou privés. 


\title{
Mechanisms involved in thermal diffusion of rare earth elements in apatite.
}

\section{P. Martin ${ }^{a}$, G. Carlot ${ }^{a}$, A. Chevarier ${ }^{a}$, C. Den-Auwer ${ }^{b}$, G. Panczer ${ }^{c}$.}

${ }^{a}$ Institut de Physique Nucléaire de Lyon, IN2P3-CNRS, 43 Bd du 11 novembre 1918, F-69622, Villeurbanne Cedex, France

${ }^{b}$ CEA/DCC/DRRV/SEMP, Marcoule, BP 171, 30207 Bagnols-s-cèze, France

${ }^{c}$ Université Claude Bernard Lyon 1, Physico-chimie des Materiaux luminescents, UMR 5620 CNRS, 43 Bd du 11 novembre 1918, F-69622, Villeurbanne Cedex,

France

\begin{abstract}
In the context of radioactive waste disposal related to the back end of the nuclear fuel cycle, we studied the diffusion of lanthanide ions in hydroxyapatite, a material considered as a possible migration barrier in the nuclear waste storage process. Lanthanum and europium have been chosen here as a representative element of the group of fission products and of actinides elements. They were introduced in apatite targets using ion implantation. Annealing in air for different times within the $400^{\circ} \mathrm{C}-600^{\circ} \mathrm{C}$ range was performed. The diffusion coefficients obtained by Rutherford Backscattering Spectroscopy analysis are low. A possible explanation is that lanthanide ions substitute the calcium ions in the apatite structure and diffuse through these positions. Time Resolved Laser Induced Fluorescence measurements show that the europium ions substitute the calcium ions in both hydroxyapatite sites $\mathrm{Ca}^{I}$ and $\mathrm{Ca}^{I I}$. Occupancy ratio between the two sites have been obtain using Extended X-ray absorption fine structure (EXAFS) measurements.
\end{abstract}

\section{Introduction}

Apatites are potentially valuable materials to be used as migration barriers for nuclear wastes disposal in deep geological sites [1][2]. They could be introduced either in containers acting as a second migration barrier in high level waste storage or in concrete structures surrounding these containers (third migration barrier). In this context, data obtained from migration studies of uranium fission in core samples surrounding the Oklo fossil reactor are of primary importance. The measured yield of rare earth proved that the lanthanide ions remain bounded not only in uranyl grains, in clays, but also in newly crystallized minerals such as hydrothermal apatites [3][4]. The aim of this work is to obtain thermodynamical data and to understand the 
mechanisms involved in thermal diffusion of lanthanide in apatites. In this paper, lanthanum and europium have been chosen as representative of fission products (A 140uma) and of actinide as the chemical properties of $\mathrm{La}^{3+}$ and $\mathrm{Eu}^{3+}$ are very similar to those of trivalent actinides. The choice of $\mathrm{Eu}^{3+}$ was dictated because of its luminescence properties. Its diffusion thermodynamical data were compared to the lanthanum ones, which mass $(\mathrm{A}=139)$ is very close to one of the maximum fission product yield. The general formula for apatite is $\mathrm{M}_{10}\left(\mathrm{PO}_{4}\right)_{6} \mathrm{X}_{2}, \mathrm{M}$ being an alkaline rare earth element and $\mathrm{X}$ being an halogen or hydroxyl ion. These minerals display a very good thermal and chemical stability as well as a very small solubility in water $\left(\mathrm{pK}_{s}=57.5\right.$ at $\left.25^{\circ} \mathrm{C}\right)[5]$. In addition, after irradiation, defects are known to recover very quickly at a temperature as low as $60^{\circ} \mathrm{C}$ [6]. Moreover, the high sorption capacity for a number of heavy elements such as actinides and lanthanides makes this material suitable for the retention of radioactive wastes. The first part of this paper is devoted to the diffusion study of both lanthanum and europium ions in the apatite structure using Rutherford Backscattering Spectroscopy. Single crystals of fluorapatite were chosen as reference samples to study the migration in the apatite lattice, while hydroxyapatite is representative of polycrystalline apatite found in sedimentary area. In the second part laser, induced luminescence Spectroscopy and EXAFS measurements have been performed in order to grab structural information around europium atoms after implantation and as function of annealing conditions.

\section{Experimental}

\subsection{Sample preparation}

Two types of apatite were studied : i) Natural mineral centimetric-size single crystals from Durango (Mexico). They were cut perpendicular to the c axis, polished and annealed in air to remove polishing damage. ii) Synthetic microcrystalline hydroxyapatite (referenced as DNA grade Bio-gel HTP) stacked into pellets at 0.4 GPa. MEB investigations showed that the grain size is about $50 \mu \mathrm{m}$ and the grain boundary width $2 \mu \mathrm{m}$.

The two lanthanide ions were implanted in both apatites : lanthanum in fluorapatite and hydroxyapatite, europium in hydroxyapatite.

Fluoro and hydroxyapatite were implanted with $100 \mathrm{keV} \mathrm{La}^{+}$ions using the isotope separator of the 'Institut de Physique Nucléaire de Lyon' (IPNL). In case of fluorapatite single crystals a tilt of few degrees of the target was applied in order to avoid channeling of La ions. For this energy the mean range $\mathrm{R}$ is about $40 \mathrm{~nm}$. The nominal dose was $5 \times 10^{15}$ ions. $\mathrm{cm}^{-2}$ corresponding to a maximum La concentration of 2.5 at\%. The beam current during implantation was typically $5 \mu \mathrm{A} . \mathrm{cm}^{-2}$. Hydroxyapatite was implanted with $200 \mathrm{keV} \mathrm{Eu}^{+}$ions. For this energy the mean range $\mathrm{R}$ is about $60 \mathrm{~nm}$. The nominal dose was $5 \times 10^{16}$ ions. $\mathrm{cm}^{-2}$ corresponding to a maximum Eu concentration of 3.5 at\%. The beam current during implantation was $5 \mu \mathrm{A} \cdot \mathrm{cm}^{-2}$. 


\subsection{Characterization techniques}

\subsubsection{Rutherford Backscattering Spectroscopy (RBS) and diffusion}

The RBS analysis was performed at the Van de Graaff accelerator (VDG) of the IPNL, using $1.5 \mathrm{MeV}$ alpha particles. The beam current was kept equal to $3 \mathrm{nA}$ in order to minimize charging and pulse pile-up effects.

\subsubsection{Luminescence}

The luminescence spectra were investigated under nitrogen UV laser $(337 \mathrm{~nm})$ excitations which delivers pulses of $10 \mathrm{~ns}$ duration and $0.1 \mathrm{~cm}^{-1}$ spectral width. The pulse energy has been maintained to about $10 \mathrm{~mJ}$. The luminescence observed at the geometry of $90^{\circ}$ was analyzed by INSTASPEC equipment enabling time-resolving spectra acquisition: delay times and strobe pulse duration between $20 \mathrm{~ns}$ and 9 ms, spectral detection range 350 - $900 \mathrm{~nm}$ (1200 channels, spectral resolution 0.5$1 \mathrm{~nm}$, gratings with 300 and 600 lines $/ \mathrm{mm}$ ), detector by intensified CCD matrix. The system was combined with optical microscope enabling spectra acquisition at micrometer scale.

\subsubsection{Extended X-ray Absorption Fine Structure (EXAFS)}

The EXAFS spectra were recorded at the DCI high energy ring of the LURE facility (Laboratoire pour l'Utilisation du Rayonnement Electromagntique, Orsay, France), operating at $1.86 \mathrm{GeV}$ with an average beam current of $300 \mathrm{~mA}$. Energy calibration was performed at the Fe K edge at $7131.3 \mathrm{eV}$. Si (111) double crystal monochromator and air filled ionization chamber detector $\left(\mathrm{I}_{0}\right)$ were used. Higher harmonics reflections were rejected by detuning the monochromator crystals by 20$30 \%$. As the europium implanted profile corresponds to about 600 nanometers depth, electron total yield detection [7] was performed in order to emphasize the surface observation compared to the bulk.

\subsection{Data Treatments}

\subsubsection{Lanthanide diffusion}

The evolution of the concentration profile of implanted species are deduced from RBS measurements [8] as a function of annealing time. The initial profiles of the as implanted samples are Gaussian distributions:

$$
C(x, t=0)=\frac{N_{i m p l}}{\sqrt{2 \Pi} \triangle R} \exp \left[-\frac{(x-R)^{2}}{2 \triangle R^{2}}\right]
$$

Here $\mathrm{C}(\mathrm{x}, \mathrm{t}=0)$ is the initial ion concentration, $\mathrm{x}$ the distance from the implanted surface, $\mathrm{N}_{\text {impl }}$ the implanted ion dose, $\mathrm{R}$ the mean range of the La or Eu ions and $\triangle \mathrm{R}$ the range straggling. In case of as implanted hydroxyapatite samples, the $\mathrm{R}$ $(36 \mathrm{~nm})$ and $\triangle \mathrm{R}(9 \mathrm{~nm})$ values deduced from RBS spectra fits are in good agreement 
with the values given by the TRIM code [9]. While in fluorapatite, due to remaining channeling effect, the $\mathrm{R}$ measured was equal to $50 \mathrm{~nm}$. Further annealing were performed in air at temperatures between $400-600^{\circ} \mathrm{C}$ and $800-1000^{\circ} \mathrm{C}$ for hydroxyapatite and fluorapatite, respectively. An upper annealing limit was set at $600^{\circ} \mathrm{C}$ for hyroxyapatite since chemical decomposition occur at higher temperature. In case of fluorapatite no migration phenomena could be observed under $800^{\circ} \mathrm{C}$ which is there the lower limit. The annealing times were in the range from 15 minutes to 3 hours. A broadening of the distributions occurs with increasing annealing time. Experimental data are interpreted on the basis of models derived from Ficks second law:

$$
\frac{\partial C}{\partial t}=D \frac{\partial^{2}}{\partial x^{2}}+f \frac{\partial C}{\partial x}
$$

where $\mathrm{C}$ is the concentration of the diffusing species, $\mathrm{D}$ is the diffusion coefficient and $f$ a driving force which can induce a shift of the whole distribution of diffusing species. It's important to notice that force don't modify the value of D. The Ficks law is a parabolic partial differential equation with one space variable. This equation is applied to a semi-infinite medium so the concentration far from the surface remains constant, i.e., $\mathrm{C}(\infty, \mathrm{t})=0$. In previous works Cherniak et al. [10][11] used analytical solutions to fit their experimental results. We have used a numerical procedure, based on the NAG FORTRAN library routine [12] to solve the Ficks second law. The input parameters are the initial distributions $(\mathrm{C}(\mathrm{x}, \mathrm{t}=0), 0<\mathrm{x}<\infty)$ and the final distributions after diffusion $(\mathrm{C}(\mathrm{x}, \mathrm{t}), 0<\mathrm{x}<\infty)$. The boundary conditions assumed in our case are : At the sample surface : $\mathrm{C}(0, \mathrm{t})=\mathrm{C}_{0}, \mathrm{C}_{0}$ being the experimental values given by the RBS simulation; $\mathrm{C}(\infty, \mathrm{t})=0$ because the medium is semi-infinite. Evolution of energy distribution with annealing conditions is presented in figure $1 \mathrm{a}$ and $1 \mathrm{~b}$ in case of fluoro and hydroxy apatites respectively.

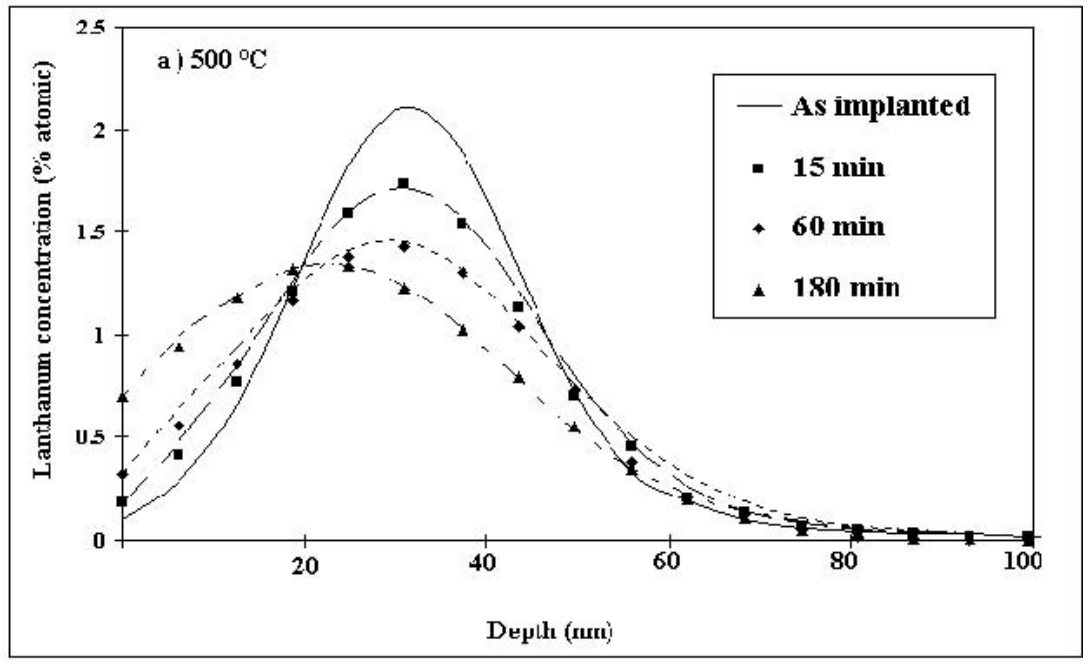




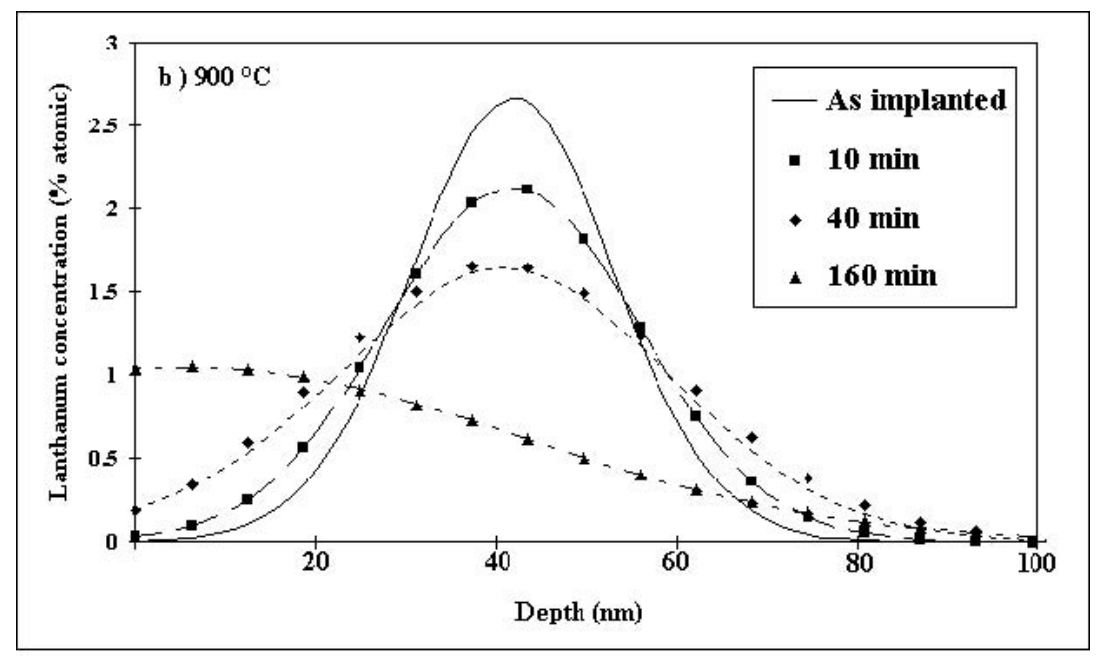

Figure 1a and 1b : Evolution of lanthanum profiles obtained by RBS (1a) in hydroxyapatite at $500^{\circ} \mathrm{C}$, and $(1 \mathrm{~b})$ in fluorapatite at $900^{\circ} \mathrm{C}$ versus annealing time.

The diffusion fits are represnted by lines.

One can notice that in fluorapatite an annealing temperature up to $800^{\circ} \mathrm{C}$ is necessary to obtain similar broadening as those observed in hydroxyapatite at $500^{\circ} \mathrm{C}$.

The diffusion coefficients were determined by using a least square method to fit the calculated distribution and the experimental one.

\subsubsection{EXAFS}

\subsubsection{Data extraction}

EXAFS oscillations are described by genera formula (3).

$$
\chi(k)=\sum_{i=1}^{N} \frac{S_{0}^{2}}{k r_{i}^{2}} N_{i}\left|f_{i}\left(\theta, k, r_{i}\right)\right| \sin \left(2 . k r_{i}+\varphi_{i}(k)+2 \cdot \delta_{c}(k)\right) \cdot e^{-2 \sigma_{i}^{2} k^{2}} \cdot e^{\frac{-2 \Pi}{\lambda}}
$$

Where $\mathrm{k}$ is the momentum of the photoelectron defined by equation (4) :

$$
k=\sqrt{\frac{8 \Pi^{2} m}{h^{2}}\left(h \nu-E_{0}\right)}
$$

Electronic parameters $\mathrm{S}_{0}^{2}, \mathrm{f}_{i}(\mathrm{~J}, \mathrm{k}, \mathrm{r}),\left(\varphi_{i}(\mathrm{k})+2 . \delta_{c}(\mathrm{k})\right)$ and $\lambda(\mathrm{k})$ are related respectively to the electronic intrinsic losses, the backscattering amplitude of the $\mathbf{i}$ contribution, the backscattering phase of the i contribution and the electron mean free path. Structural parameters $\left(\mathrm{N}_{i}, \mathrm{r}_{i}, \sigma_{i}\right)$ are respectively related to the numbers of neighbors, the absorbing atom to neighbor distance and the Deby-Waller factor for each i contribution. The oscillations were extracted using EXAFS power code from A. Mikalowitch [13]. Linear extrapolation was used to remove background contribution and five order polynomial function was used to model atomic absorption before Lengeler-Eisenberger normalization. Fourier transformation (FT) in $\mathrm{k}^{3}$ was 
performed between 0.14 and $1.03 \mathrm{~nm}$ with Kaiser apodization window $(\tau=2.5)$. Inverse Fourier transformation was carried out between 0.14 and $0.4 \mathrm{~nm}$.

\subsubsection{Fitting procedure}

Phase shift, amplitude of the Backscattering wave function and 1 were calculated using the FEFF702 simulation code [14] from S.I. Zabinsky et al. using apatite structure [15] at the Eu $\mathrm{L}_{I I I}$ edge, as fully described elsewhere [16]. Least square fitting of the experimental EXAFS oscillations were performed with "Round Midnight" code from A. Mikalowitch [13] in the single scattering approximation. For all fits, $\mathrm{S}_{0}^{2}$ was set to 1 and $\mathrm{E}_{0}$ was set to $6983 \mathrm{eV}$.

\section{Results}

\subsection{Diffusion}

The diffusion coefficient values obtained for lanthanum and europium in fluorapatite are $1.6 \times 10^{-15}$ at $1000^{\circ} \mathrm{C}$ and $1.1 \times 10^{-16} \mathrm{~cm}^{2} \cdot \mathrm{s}^{-1}$ at $800^{\circ} \mathrm{C}$. These results are in good agreement with the data obtained for lanthanum, samarium and lutetium in ref [17]. In hydroxyapatite similar diffusion coefficient values for europium and lanthanum are obtained and they are equal to $6 \times 10^{-15}$ and $2.3 \times 10^{-17} \mathrm{~cm}^{2} \cdot \mathrm{s}^{-1}$ at $600^{\circ} \mathrm{C}$ and $400^{\circ} \mathrm{C}$ respectively. The activation energies and preexponential factors deduced from the Arrhenius plot (figure 2) are $1.3 \mathrm{eV} \cdot \mathrm{at}^{-1}$ and $1.3 \times 10^{-7} \mathrm{~cm}^{2} . \mathrm{s}^{-1}$ for hydroxyapatite and $2.1 \mathrm{eV} \cdot \mathrm{at}^{-1}$ and $5.1 \times 10^{-7} \mathrm{~cm}^{2} . \mathrm{s}^{-1}$ for fluorapatite for lanthanide ions.

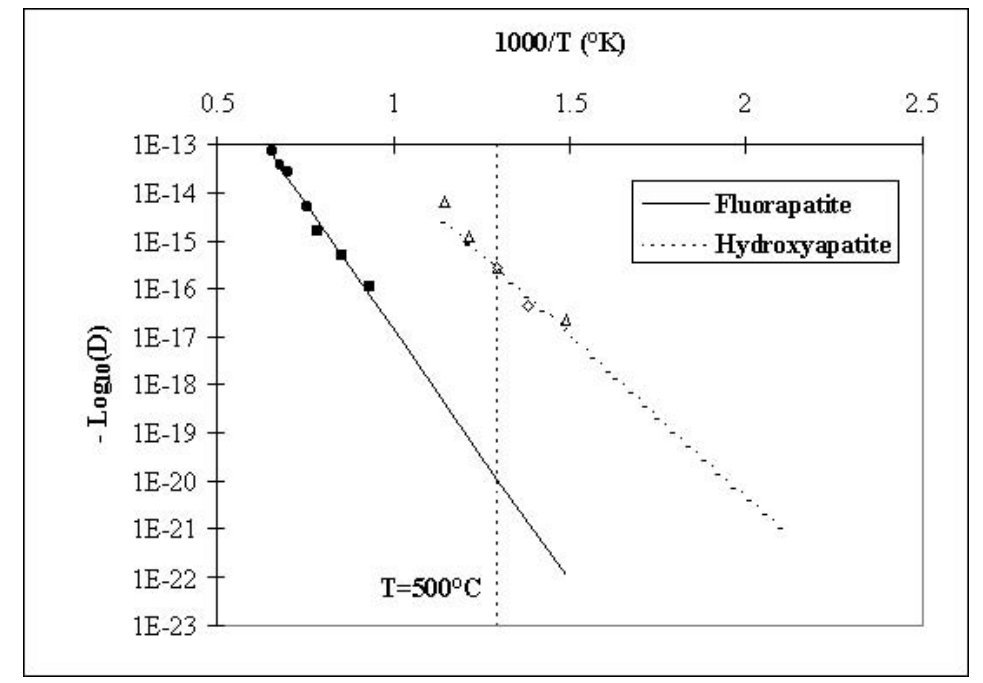

Figure 2 : Arrhenius diagram corresponding to hydroxyapatite and fluorapatite. Preexponential factors and activation energies are deduced from extrapolation (dashed and full lines)

A more rapid lanthanide ions diffusion in hydroxyapatite compared to the single crystal is observed (for example at $500^{\circ} \mathrm{C} 4.4 \times 10^{-16} \mathrm{~cm}^{2} \cdot \mathrm{s}^{-1}$ to be compared with 
$\left.6.2 \times 10^{-21} \mathrm{~cm}^{2} \cdot \mathrm{s}^{-1}\right)$. This is very likely due to the presence of grain boundaries which facilitate the diffusion process. Meanwhile, diffusion coefficients are found to be low compared to those obtained in other materials. It might be explain the remarkable immobilization of lanthanide in the apatite lattice

\subsubsection{Microluminescence}

It has been known for a long time that natural and synthetic apatite are fluorescent. By steady-state spectroscopy it was discovered that its luminescence is determined by characteristic bands of rare earth elements [18]. Trivalent europium ions are widely used as luminescent probes in the investigation of the crystallographic structure of the activator centers [18]. The ${ }^{7} \mathrm{~F}_{0} \longrightarrow{ }^{5} \mathrm{D}_{0}$ transition is particularly informative ; as a matter of fact each $\mathrm{Eu}^{3+}$ center induces a specific emission line for this transition while the relative intensity is characteristic of the local symmetry [19]. The apatite structure, $\mathrm{Ca}_{10}\left(\mathrm{PO}_{4}\right)_{6}(\mathrm{OH})_{2}$, with symmetry group $\mathrm{P} 63 / \mathrm{m}$ presents two types of Ca site : $\mathrm{Ca}(\mathrm{I})$ with $\mathrm{C}_{3}$ symmetry surrounded by 9 oxygen and $\mathrm{Ca}(\mathrm{II})$ with $\mathrm{C}_{s}$ symmetry surrounded by 6 oxygens and $1\left(\mathrm{OH}^{-}\right)$ion [18][20]. The emission spectrum of the non heated implanted pellet show very weak luminescent bands (fig. 3).

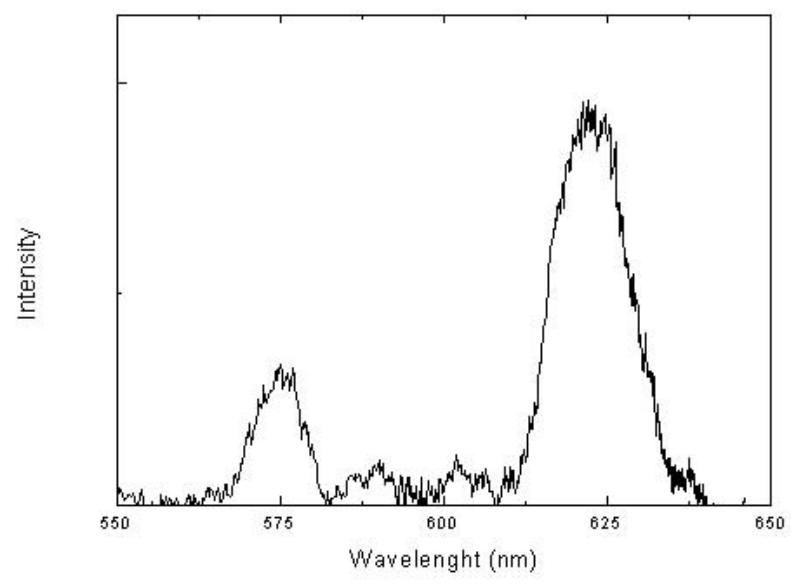

Figure 3 : Luminescence spectra ( $\lambda_{e} x c 337 \mathrm{~nm}$, delay : 500ns, gate width : 5ms) of as implanted apatite 

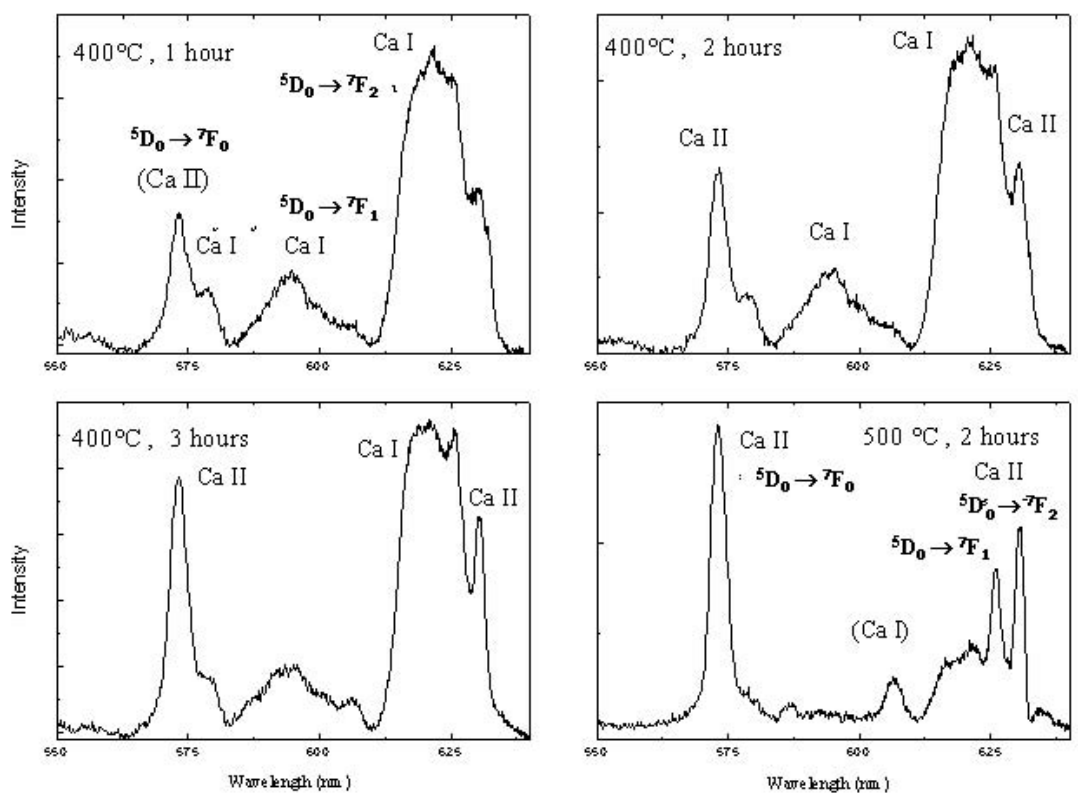

Figure 4 : Luminescence spectra ( $\lambda_{e} x c 337 \mathrm{~nm}$, delay : 500ns, gate width $: 5 \mathrm{~ms})$ of thermally treated apatite (biorad) implanted with europium $\left(5.10^{16}\right.$ atoms.cm ${ }^{-2}$ at $200 \mathrm{keV}$ ) .

The samples heated during 1 hour at $400^{\circ} \mathrm{C}$ present an emission spectra with specific transitions of $\mathrm{Eu}^{3+}$ in $\mathrm{Ca}(\mathrm{I})$ site corresponding to lines at 621.5, 595 and 579 $\mathrm{nm}$ (Fig. 4). For longer annealing times, new bands appear at 630, 626 and 573.5 $\mathrm{nm}$. Their intensity increases with time (2 and 3 hours fig 4 ) while previous line intensity decreases progressively. The same behavior is observed at $500^{\circ} \mathrm{C}$ and leads to complete disappearance of the $\mathrm{Ca}(\mathrm{I})$ emission lines after only 2 hours annealing (fig 4). The first set of emissions bands with the main one at $621 \mathrm{~nm}$ corresponds to the ${ }^{5} \mathrm{D}_{0} \longrightarrow{ }^{7} \mathrm{~F}_{x}$ transitions of $\mathrm{Eu}^{3+}$ in high $\mathrm{C}_{3}$ symmetry $\mathrm{Ca}(\mathrm{I})$ position while the second set with the main line at $573 \mathrm{~nm}$ corresponds to the same transitions of $\mathrm{Eu}^{3+}$ but in the low $\mathrm{C}_{s}$ symmetry $\mathrm{Ca}(\mathrm{II})$ position [21]. The weakness of the emission before any thermal induced diffusion indicates that the majority of the europium ions is adsorbed on the surface of the apatite crystallites target. However the energy of implantation allows the partial fixation of the europium ions inside the apatite lattice by substitution of $\mathrm{Ca}^{2+}$ in $\mathrm{Ca}(\mathrm{I})$ position. It is only in such crystallographic environment that the radiative transitions can occur. Providing thermal energy induces as a function of time the diffusion of the europium ions and the substitution in $\mathrm{Ca}(\mathrm{I})$ sites. The oxidizing environment allows the charge compensation between $\mathrm{eu}^{3+}$ and $\mathrm{Ca}^{2+}$. At $400^{\circ} \mathrm{C}$, the diffusion of $\mathrm{Eu}$ from $\mathrm{Ca}$ (I) to $\mathrm{Ca}$ (II) sites occurs and over $500^{\circ} \mathrm{C}$ the complete migration to $\mathrm{Ca}$ (II) position is achieved. 


\subsection{EXAFS}

\subsubsection{Analysis of EXAFS spectrum of pure hydroxyapatite at the Ca K edge.}

Hydroxyapatite has a rather complex crystal structure in which the unit cell contains $2 \mathrm{Ca}_{10}\left(\mathrm{PO}_{4}\right)_{6}(\mathrm{OH})_{2}$ units. Furthermore 4 calcium ions occupy the $\mathrm{Ca}(\mathrm{I})$ site and 6 occupy the $\mathrm{Ca}$ (II) site. Such a structure corresponds to a wide range of distances between the calcium and the oxygen atoms and leads to an extremely complex averaged EXAFS spectrum. In order to simplify, we consider average distances of oxygen shells.

To valid the fitting parameters to be used when the Eu ions substitute the calcium ions in both $\mathrm{Ca}(\mathrm{I})$ and $\mathrm{Ca}(\mathrm{II})$ sites, the EXAFS spectrum of free hydroxyapatite has been fitted. Fourier transform of the experimental spectrum at the Ca $\mathrm{K}$ edge is given in figure 5 and exhibits two regions ( 1 and 2) that were fitted using FEFF7.02 phases and amplitudes from the apatite crystallographic structure [15].

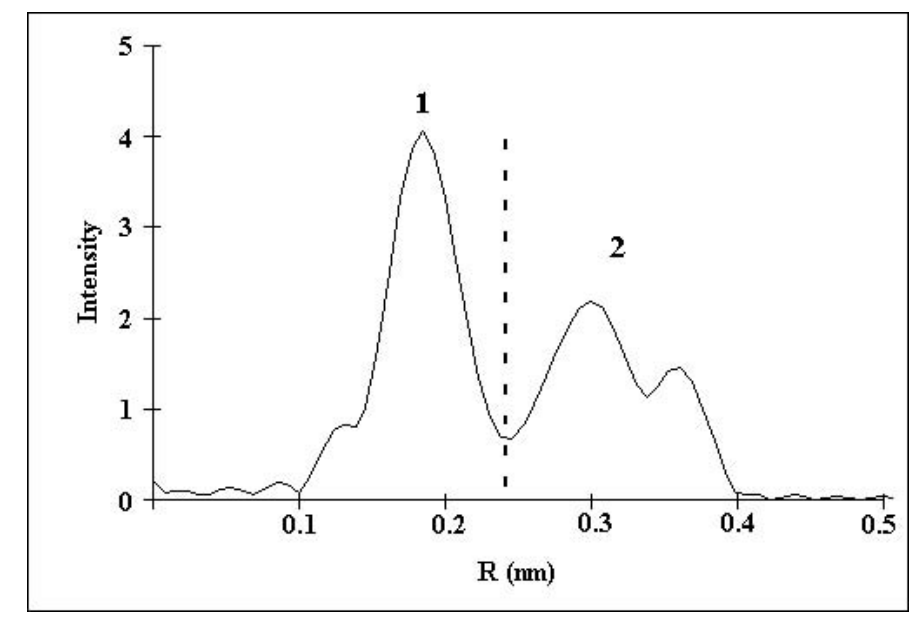

Figure 5 : Fourier transformation of $\mathrm{k}^{3}$-weighted EXAFS spectrum for hydroxyapatite sample. Radial distribution functions were not corrected for phase shift. The two components are delimited by vertical dashed lines

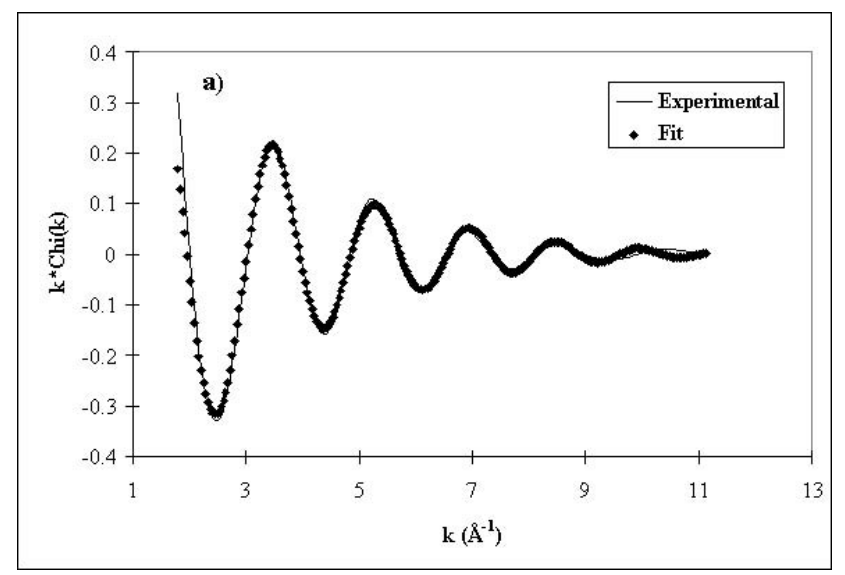




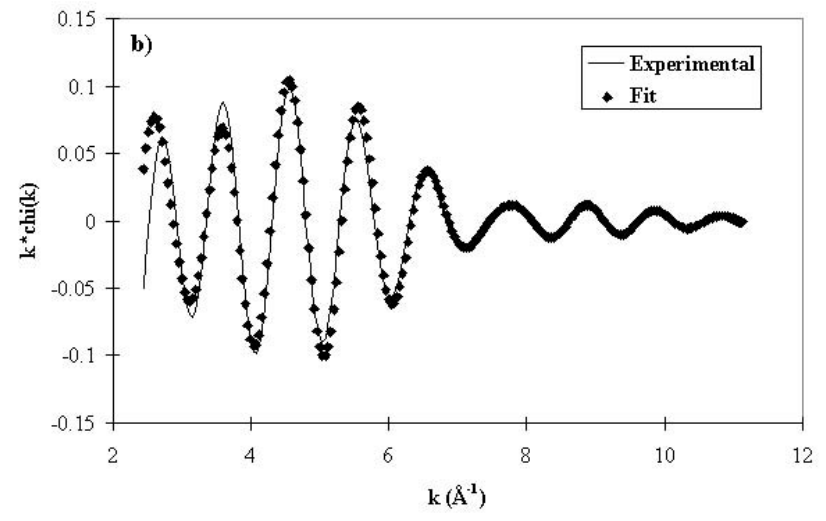

Figure 6a and 6b : Fourier-filtered first(a) and second (b) component to EXAFS for fitted with FEFF7 code calculation.

\begin{tabular}{|c|c|c|c|c|c|}
\hline & \multirow{3}{*}{$\mathrm{N}$} & \multirow{3}{*}{$\begin{array}{l}\mathrm{R}(\mathrm{nm}) \\
\text { EXAFS }\end{array}$} & \multirow{3}{*}{$\begin{array}{c}\mathrm{R}(\mathrm{nm}) \\
\mathrm{X}-\mathrm{R} \text { ay }[15]\end{array}$} & \multirow{3}{*}{$\sigma(\mathrm{nm})$} \\
\hline & & & & & \\
\hline & & & & & \\
\hline \multirow{3}{*}{ Region 1} & $\mathrm{Ca}-\mathrm{O}$ & 6.6 & $0.241 \pm 0.0005$ & 0.242 & $0.0099 \pm 0.0005$ \\
\hline & $\mathrm{Ca}-\mathrm{O}$ & 1.8 & $0.273 \pm 0.0005$ & 0.275 & $0.0100 \pm 0.0005$ \\
\hline & $\mathrm{Ca}-\mathrm{P}$ & 2.4 & $0.320 \pm 0.0001$ & 0.320 & $0.0136 \pm 0.0002$ \\
\hline \multirow{4}{*}{ Region 2} & $\mathrm{Ca}-\mathrm{Ca}$ & 0.8 & $0.345 \pm 0.0001$ & 0.344 & $0.0075 \pm 0.0002$ \\
\hline & Ca-P & 3 & $0.360 \pm 0.0001$ & 0.360 & $0.0134 \pm 0.0002$ \\
\hline & $\mathrm{Ca}-\mathrm{Ca}$ & 6 & $0.406 \pm 0.002$ & 0.406 & $0.0137 \pm 0.0002$ \\
\hline & & \multicolumn{4}{|c|}{$\mathrm{r}$ factor $=2.42 \times 10^{-2}$} \\
\hline
\end{tabular}

Table 1 : Average calcium environment for hydroxyapatite as determined by $\mathrm{X}$-ray crystallography and EXAFS $\mathrm{C}$ ( $\mathrm{N}=$ number of neighbors, $\mathrm{R}=$ distance, $\mathrm{s}=$ Debye-Waller factor).

Best fit parameters are given in table 1 and compare well with the crystallographic data. Furthermore, these results are backed by those obtained by J.E. Harries et al. [22]. The fitting procedure and parameters used here are thus valid to be used for Europium implanted apatite.

\subsubsection{Analysis of EXAFS spectrum of implanted hydroxyapatite at the europium $\mathrm{L}_{I I I}$ edge.}

As the luminescence study emphasizes the high probability of substitution in $\mathrm{Ca}$ (II) site after 2 hours annealing at $500^{\circ} \mathrm{C}$, we performed EXAFS measurements after the same annealing conditions to precise the Eu environment. Prior to any 
EXAFS data analysis we supposed that all the europium ions are in $\mathrm{Ca}$ (I) or $\mathrm{Ca}$ (II) substitution sites. Such an approximation is backed by the relativity high annealing temperature set point that ensures major migration of $\mathrm{Eu}^{3+}$ into $\mathrm{Ca}(\mathrm{II})$ sites, as suggested by the fluorescence measurements. Furthermore, the atomic concentration of implanted europium is strictly inferior to the doping limit of hydroxyapatite (5\%) [23]. In order to simulate the $\mathrm{Ca}(\mathrm{II}) / \mathrm{Ca}(\mathrm{I})$ substitution ratio we performed several FEFF7.02 simulations at the Eu $\mathrm{L}_{I I I}$ edge. Resulting Fourier transforms are given in figure 7 and correspond to parameters evolution as shown in figure $8 \mathrm{a}$ and $8 \mathrm{~b}$.

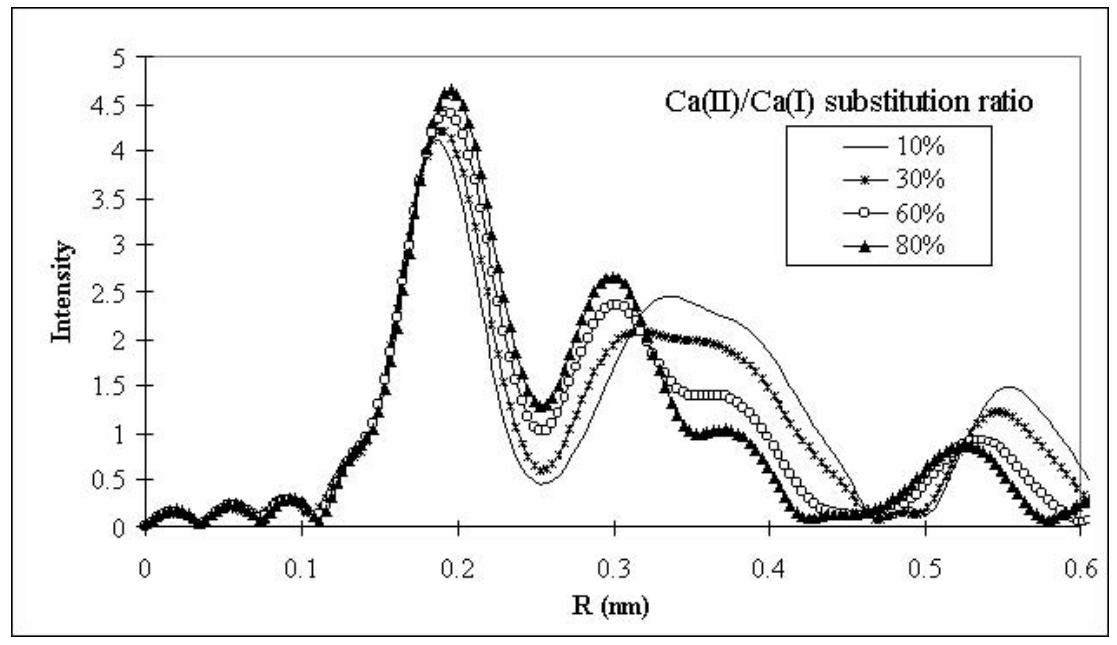

Figure 7 : Fourier transform of EXAFS spectra obtained by FEFF7.02 as function $\mathrm{Ca} 2 / \mathrm{Ca} 1$ substitution ratio.

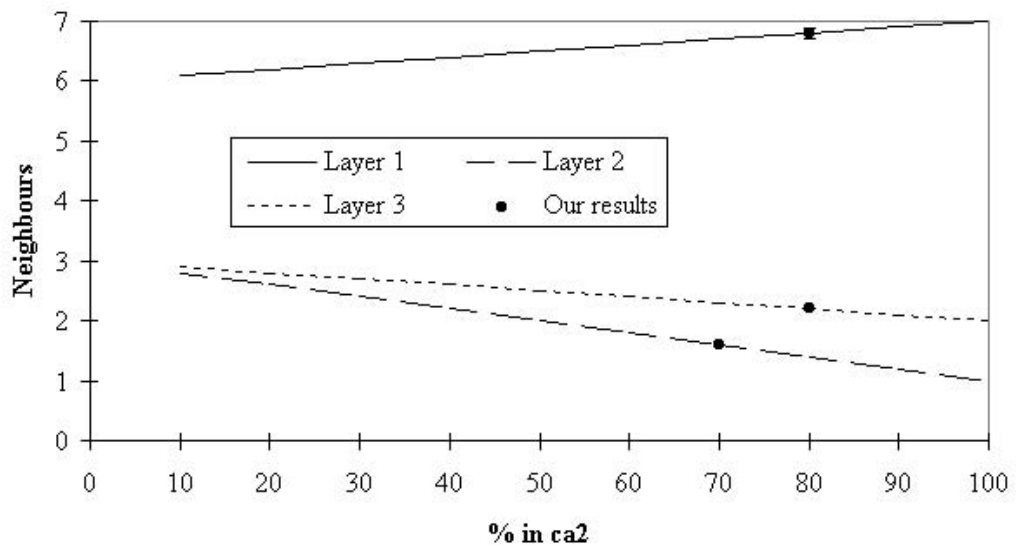




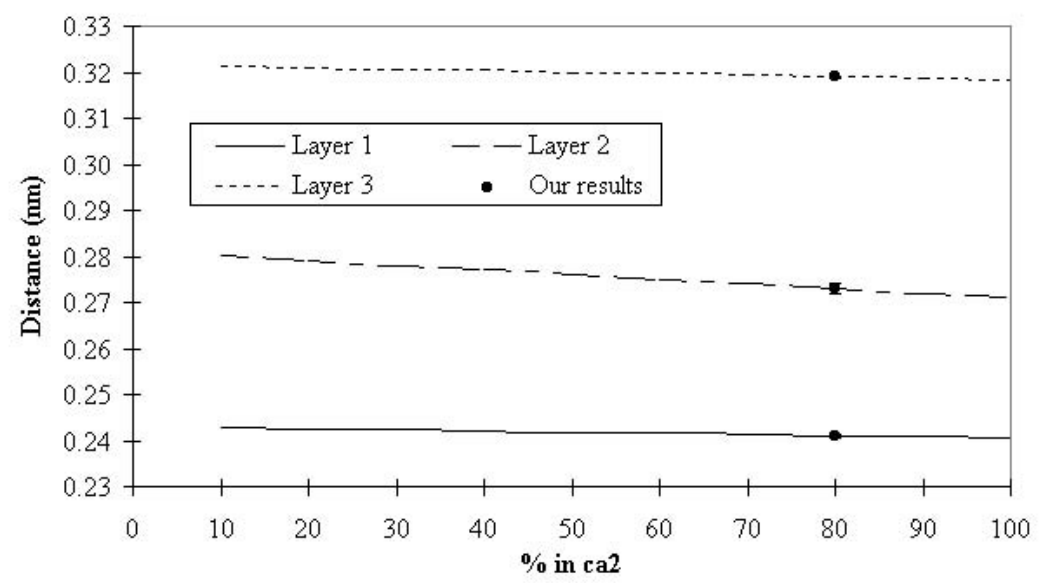

Figure 8a and $8 \mathbf{b}$ : Fourier transform of EXAFS spectra obtained by FEFF7.02 as function $\mathrm{Ca}(\mathrm{II}) / \mathrm{Ca}(\mathrm{I})$ substitution ratio.

\begin{tabular}{|l|c|c|c|}
\cline { 2 - 4 } \multicolumn{1}{c|}{} & $N$ & $\mathrm{R}(\mathrm{nm})$ & $\sigma(\mathrm{nm})$ \\
\hline Eu-O & $6.80 \pm 0.09$ & $0.241 \pm 0.0004$ & $0.0099 \pm 0.0001$ \\
& & & $0.0100 \pm 0.003$ \\
\hline Eu-O & $1.40 \pm 0.01$ & $0.273 \pm 0.001$ & $0.0136 \pm 0.001$ \\
\hline Eu-P & $2.20 \pm 0.02$ & $0.319 \pm .0002$ & \multicolumn{3}{|c|}{$r$ factor $=4.80 \times 10^{-2}$} \\
\hline
\end{tabular}

Table 2 : Best fit EXAFS parameters corresponding to four hours annealing at $500^{\circ} \mathrm{C}(\mathrm{N}=$ number of neighbors, $\mathrm{R}=$ distance, $\mathrm{s}=$ Debye-Waller factor $)$.

\begin{tabular}{|c|c|c|c|}
\cline { 2 - 4 } \multicolumn{1}{c|}{} & $N$ & $R(\mathrm{~nm})$ & $\sigma(\mathrm{nm})$ \\
\hline Eu-O & $6.80 \pm 0.09$ & $0.241 \pm 0.0004$ & $0.0099 \pm 0.0001$ \\
\hline Eu-O & $1.20 \pm 0.01$ & $0.273 \pm 0.001$ & $0.0100 \pm 0.003$ \\
\hline Eu-P & $2.20 \pm 0.02$ & $0.319 \pm .0002$ & $0.0136 \pm 0.001$ \\
\hline & \multicolumn{3}{|c|}{ r factor $=5.70 \times 10^{-2}$} \\
\cline { 3 - 4 } & & \multicolumn{3}{c|}{}
\end{tabular}

Table 3 : Best fit EXAFS parameters corresponding to three hours annealing at $500^{\circ} \mathrm{C}(\mathrm{N}=$ number of neighbors, $\mathrm{R}=$ distance, $\mathrm{s}=$ Debye-Waller factor $)$.

Best fit parameters given in tables 2 and 3 correspond to the adjustment of the experimental EXAFS spectra corresponding for $500^{\circ} \mathrm{C}$ annealing for 4 and 3 hours. 
Fit is represented in figure 9. Comparison with figures $8 \mathrm{a}$ and $8 \mathrm{~b}$ suggest that $80 \%$ of $\mathrm{Eu}^{3+}$ are substituted to $\mathrm{Ca}(\mathrm{II})$ sites after 3 hours and this percentage remains the same after 4 hours. These values are very similar and no strong evolution after 3 hours annealing is observed.

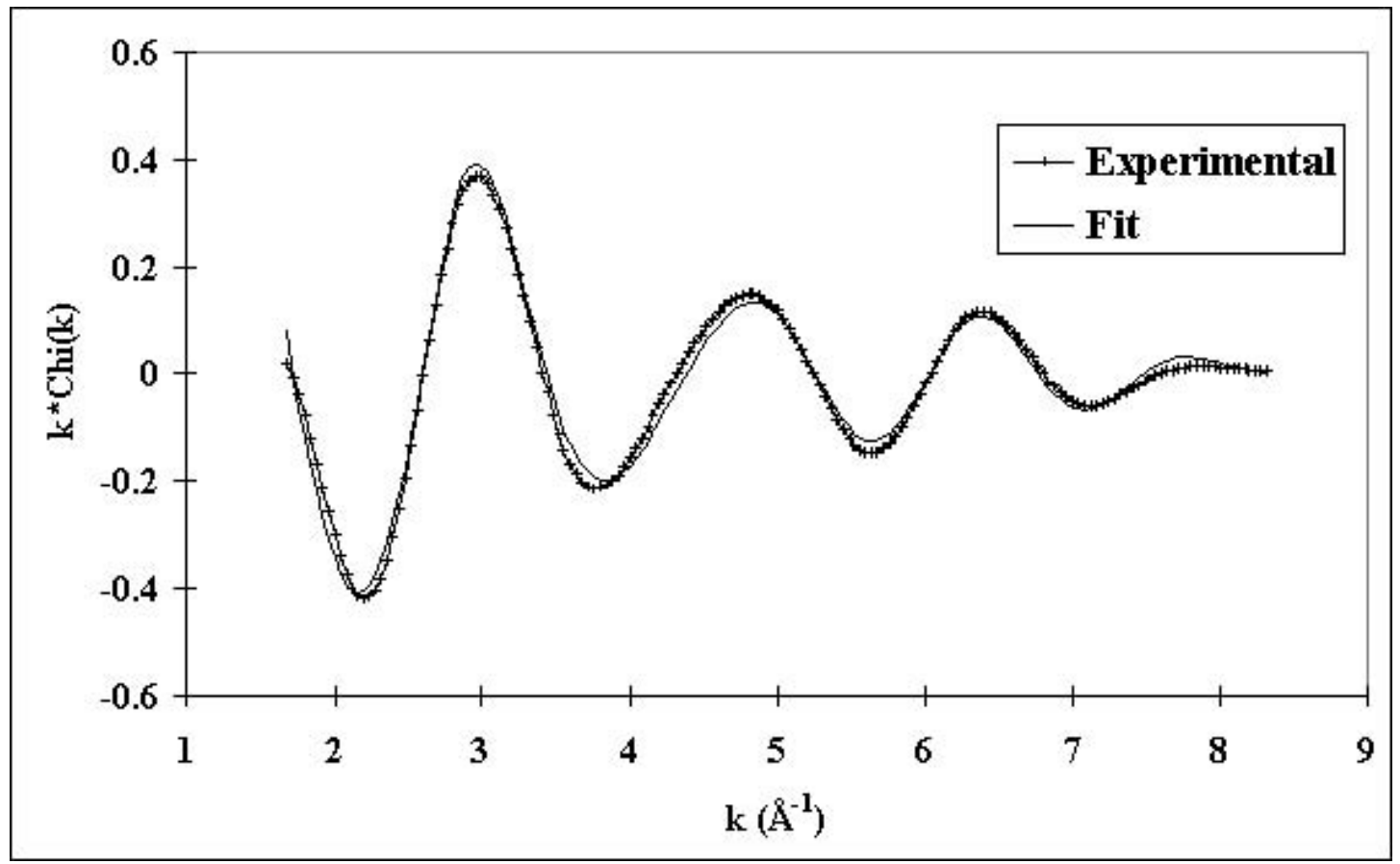

Figure 9 : Fourier-filtered to EXAFS for fitted with FEFF7 code calculation.

\section{Discussion}

Both luminescence and EXAFS data suggest that rate of lanthanide ions substituted to the calcium sites in the apatite structure increases with annealing times. Furthermore, the substitution ratio $\mathrm{Ca}(\mathrm{II}) / \mathrm{Ca}(\mathrm{I})$ increases. After 3 hours at $500^{\circ} \mathrm{C}$ for instance, about $80 \%$ of europium ions are located in the $\mathrm{Ca}(\mathrm{II})$ site. These results are in agreement with the site occupation ratio $\mathrm{Ca}(\mathrm{II}) / \mathrm{Ca}(\mathrm{I}) \sim 4$ determined by Fleet and al [24]. in case of lanthanum doped synthetic fluorapatite crystals. In case that case, charge compensation occur because of the divalent and trivalent states of calcium and europium respectively. We propose here a simple substitution mechanism that implies the contribution of other species. In our experimental conditions (annealing under air), substitution of trivalent lanthanide ions in hydroxyapatite could be compensated as follows:

○ Mechanism 1 : substitution of $\mathrm{OH}^{-}$by $\mathrm{O}_{2}^{-}$

$$
\mathrm{Eu}^{3+}+\mathrm{O}^{2-} \longleftrightarrow \mathrm{Ca}^{2+}+\mathrm{OH}^{-} \quad \mathrm{Ca}_{10-x} E u_{x}\left(\mathrm{PO}_{4}\right)_{6}(\mathrm{OH})_{2}
$$

It must be noted that the $\mathrm{Ca}(\mathrm{II})$ position is located near the $\mathrm{OH}$ - lattice columns, and this could increase the probability of such a mechanism as far as oxygen diffu- 
sion through these columns is possible.

- Mechanism 2 : substitution of $\mathrm{Ca}^{2+}$ by a vacancy $(\Theta)$

$$
2 E u^{3+}+\Theta \longleftrightarrow 3 \mathrm{Ca}^{2+} \quad \mathrm{Ca}_{10-3 x} E u_{x} \Theta_{x}\left(\mathrm{PO}_{4}\right)_{6}(\mathrm{OH})_{2}
$$

Let us now connect these results to diffusion data. In case of both single crystal and polycrystalline apatite we can notice a slight shift of the lanthanide ions distribution toward the surface. In order to the modeling the evolution of lanthanide atomic concentration profiles a driving force as to be introduced in the second Fick's Law. Such a driving force allows to take into account the slight shift of lanthanide distribution. As specify previously application of a constant depth driving force in the Fick's second law do not modify the extracted diffusion coefficient values but the challenge is to understand the physical meaning of this driving force.

The major annihilation process for defects is known to be their diffusion to the sample surface [25]. One possible explanation to the lanthanide migration towards the surface could be the influence of defects created by implantation process. However, such an assumption has to be precluded because at annealing temperature larger than $400^{\circ} \mathrm{C}$ the defects recover very quickly (few seconds [6]). Moreover, a defect enhanced diffusion presents a non Fickian profile evolution, this is not the case here. Therefore, no influence on the diffusion process is to be attributed to the defects. The alternative is to connect the lanthanide distribution shift to mechanism 1. In order to achieve charge compensation for all the lanthanide ions introduced in the samples a large amount of oxygen is needed ( $4 \%$ atomic). The only oxygen supply is provided by oxygen diffusion from the surface. Oxygen diffusion in fluoarapatite from the surface has been studied by Farver it et al. [26]. They determined a diffusion coefficient at $800^{\circ} \mathrm{C}$ which stands between $3 \times 10^{-15} \mathrm{~cm}^{2} . \mathrm{s}^{-1}$ for a $200 \mathrm{bar}$ pressure and $1 \times 10^{-14} \mathrm{~cm}^{2} \cdot \mathrm{s}^{-1}$ for a 2000 bar pressure. Extrapolation of these data to our experimental conditions leads to a diffusion coefficient value around $10^{-17}$ $\mathrm{cm}^{2} \cdot \mathrm{s}^{-1}$ which corresponds to a slower process than the one we observed here. In our system an oxygen concentration gradient appears from the surface to the bulk and generates a chemical potential. This potential leads to the preferential flux of lanthanide to the surface in order to obey charge compensation. This assesses that mechanism 1 is the dominant process for diffusion under air. Meanwhile, mechanism 1 is also backed by the fact that in case of rare earth diffusion under vacuum only substitution in $\mathrm{Ca}(\mathrm{I})$ is observed [21].

In this work, we conclude that the preferential mechanism in lanthanide divalent ions migration under air lead to substitution to $\mathrm{Ca}$ (II) site in apatite lattice. This explain the very low diffusion coefficients that were observed (i.e. $3 \times 10^{-25} \mathrm{~cm}^{2} . \mathrm{s}^{-1}$ for hydroxypatite at $100^{\circ} \mathrm{C}$ ). Such results are speaking in favor of apatites as filling materials in geological disposal. However, we must be aware that slight migration of lanthanide toward the surface has been observed and this may potentially make this material more easily damaged by water lixiviation. 


\section{References}

[1] : R. C. Ewing, W. J. Weber and F.W. Clinard Jr., Progress in Nuclear Energy 29 (1995) 63.

[2] : R. Gauglitz, M. Holterdorf, W. Franke and G. Marx, Radiochemica Acta $58 / 59$ (1992) 253.

[3] : F. Gauthier-Lafaye, P. Holliger and P. P. Blanc, Geochimica et Cosmochimica Acta 60 (1996) 4831.

[4] : P.L. Blanc, F. Gauthier-Lafaye, P. Holliger, A. Winberg, E. Ledoux, I. Gurban, CEA- IPSN report (1995) FI2W-CT91-0071.

[5] : S. Chander and D.W. Fuerstenau, in Solubility and interfacial properties of hydroxyapatite : a review D.N. Misra (Ed), Plenum Press, New York, 1984, p. 129.

[6] : F. Villa, étude de l'évolution structurale des traces latentes de fission dans l'apatite au cours d'un recuit thermique. Mise en œuvre d'une simulation de la révélation chimique, Université Franche Comté Thesis, 1997.

[7] : J. Mimault, J.J. Faix, T. Girardeau, M. Jaouen and G. Tourillon, Meas. Sci. Technol. 5 (1994) 484.

[8] : N. Moncoffre, G. Barbier, E. Leblond, P. Martin and H. Jaffrezic, Nucl. Instr. And Meth. in Phys. Res.B, 140 (1998) 402.

[9] : J. P. Biersack and L. G. Haggmark, , Nucl. Instr. and Meth., 174 (1980) 257.

[10] : D.J. Cherniak, W.A. Lanford and F.J. Ryerson, Geochimica et Cosmochimica Acta, 55 (1991) 1663.

[11] : D.J. Cherniak and F.J. Ryerson, Geochimica et Cosmochimica Acta, 57 (1993) 4653.

[12] : NAGLIB Manual-FORTRAN, Mark 8, Vol.2, D03PAF, (1981).

[13] : A. Michalowicz, Société Française de chimie, 116 (1991) 45.

[14] : S.I. Zabinsky, J.J. Rher, A. Ankudinov, R.C. Albers and M.J. Eller, Phys. Rev. B. 52 (1995) 2995.

[15] : M.I. Kay and R.A. Young, Nature, 204 (1964) 1050.

[16] : P. Martin, étude des mécanismes de diffusion des terres rares dans les apatites soumises á irradiation alpha, University Lyon1, 1999.

[17] : Diffusion of $\mathrm{Sm}, \mathrm{Sr}$, and $\mathrm{Pb}$ in fluorapatite, E.B. Watson, T.M. Harrison, F.M. Ryerson, Geochimica et Cosmochimica Acta, 1985, Vol. 49, pp. 1813-1823. 
[18] : R. Jagannathan and M. Kottaisamy, J. Phys. Condens. Matter., 7 (1995) 8453.

[19] : M. Kottaisamy, R. Jagannathan, P. Jeyagopal, R.P. Rao and R. L. Narayan, J. Phys. D : Appl. Phys., 27 (1994) 2210.

[20] : R. Knubovets, Rev. Chem. Eng., 9 (1993) 161.

[21] : M. Gaft, R. Reisfeld, G. Panczer, S. Shoval, B. Champagnon and G. Boulon, J. Lumin. 72-74 (1997) 572.

[22] : J.E. Harries, D.W.L. Kukins and S.S. Hasnain, J. Phys. C: Solid State Phys. 19 (1986) 6859.

[23] : M. Mikou, A. taitai and J.L. Lacout, Ann. Chim. Fr. 10 (1985) 645.

[24] : M.E. Fleet and Y. Pan, American Mineralogist 80 (1995) 329.

[25] : E. Bertel, W. Ritter, E. Bertagnolli and T.D. Mark, Phys. Rev. B 27 (1983) 3730 .

[26] : J.R. Farver, B.J. Giletti, Geochimica et Cosmichimica Acta 53 (1989) 1621. 